\title{
Engaging Prospective Engineers in Math Education THROUGH ROBOTICS AND KNOWLEDGE BUILDING
}

\author{
Ahmad Khanlari \\ University of Toronto \\ a.khanlari@mail.utoronto.ca
}

\begin{abstract}
Robotics, with its multidisciplinary nature, integrates Science, Technology, Engineering, and Mathematics (STEM) disciplines and is considered a gateway to STEM education. When integrating robotics into teaching activities, most educators employ Competition-Based Learning (CBL) approach. CBL may diminish robotics potential, because competitions may discourage active construction of knowledge and the development of talent by isolating students. This study aims to use robotics to teach math concepts to students. In order to address the concerns regarding competitions, I employ knowledge building pedagogy and technology and explore which approach is more effective for learning: Knowledge Building or Competition Based Learning. The preliminary results show that employing Knowledge Building results in a better outcome, in terms of learning math concepts.
\end{abstract}

\section{INTRODUCTION}

A review of the literature shows that robotics promotes development of problem-solving skills, creativity, critical thinking, and collaboration and team work skills along with better understanding of Science, Technology, Engineering, and Mathematics (STEM) (e.g., [1]-[3]). It has been claimed in some studies (e.g. [4]) that Competition Based Learning (CBL) is the most effective way to integrate robotics into subjects such as math and physics. In CBL, students build and program their robots in order to accomplish challenges, beat others and get credit [4]. Some studies demonstrated that robotics competitions provide engaging contexts for learning STEM subjects and promote students' interests toward STEM-related fields (e.g. [5], [6]). Hence, researchers and educators have widely

employed CBL to integrate robotics ([7], [8]).

Although the concept of competition in education is supported by several studies (e.g., [9], [10]), there are several concerns in regards to competitions in education. One concern is that competitions usually focus on winning, while education should focus on processes that ultimately result in success [11]. Therefore, competitions may have negative effects on the learning process, and force students to focus on a limited set of "winning" goals rather than a process more attuned to deep understanding [12], [13]. This concern is true for robotics competitions as well. For instance, Hallak, Armoni, and Ben-Ari in [14] stated that sometimes learning opportunities were sacrificed by students in favor of building robots to accomplish the challenges: students were unable to explain important robotics concepts because they had just memorized the information to operate their robots. Another concern is that during competitive activities, communication and helping others is usually minimized because students usually perceive their goals as only being reached if other students fail to achieve their goals [15]. In fact, the growing emphasis on the final products of competitive activities sometimes leads students to disregard other goals such as groups' interactions, collaboration and shared vision [16]. Therefore, competitions may "discourage active construction of knowledge and the development of talent by isolating students" [15]. Such a learning environment creates a dichotomy in which talented students are the winners at the expense of less talented students. In robotics competitions, like other competitive activities, it is very common to have some really developed projects and some projects in their early stages of development. For example, Hallak and colleagues stated that only a few groups of students could successfully complete their robots to accomplish the challenges.

Moreover, although the relative quality of products may be an indicator of winning a contest, winning the competition does not necessarily mean that students are doing their best, because trying to beat others is different than trying to do well [17]. One potential solution for these challenges and 
concerns is to teach robotics employing collaborative approaches. Kohn stated that students' discussions in cooperative and collaborative environments develop "higher quality cognitive strategies for learning than does the individual reasoning found in competitive and individualistic learning situations," leading students to produce more complex products (p. 50). Therefore, some researchers employed a collaborative approach in which students formed small groups to collaboratively accomplish robotics projects (e.g., [18]). Although small-scale collaboration has the potential to mitigate the negative effects of robotics competitions, it has its drawbacks as well. For example, the results of a study showed that several teams could not complete the robotics projects, and the average completion rate was $68 \%$ [19]. In fact, information in small groups is not readily available to the full group, thus less likely to spread and be built on [20]. Engaging students in a large-scale collaboration, in which students collaborate with all other students, may result in fewer students at the periphery. Is it possible to create an environment in which students collaborate with each other not because of prizes, but because they are committed to sharing knowledge with others, to supporting newcomers and those less inclined to be involved, and to learning from others? Knowledge Building theory, pedagogy and technology has the potential to create such a community in which innovations and knowledge are democratized for the benefit of all. To create such a community, I employ knowledge building pedagogy and technology, whose aim is to create a community knowledge, resulting in producing knowledge of value to others, and advancing the knowledge of the community. In this study, I aim to engage students in robotics while exploring math concepts, and examine which approach is more effective for learning: Knowledge Building or Competition Based Learning.

\section{THEORETICAL FRAMEWORK}

Scardamalia and Bereiter in [21] presented 12 principles that altogether describe Knowledge Building as a principle-based pedagogy and that are set forth to make knowledge creation more accessible to teachers and students. These 12 principles frame Knowledge Building as an idea-centered pedagogy with students as epistemic agents, creating knowledge through engaging in complex socio-cognitive interactions in which students create community knowledge. Knowledge Building places great emphasis on the notion of community and collective responsibility for knowledge advancement. In such a community, students are encouraged to advance community knowledge through participation in progressive discourse [22] and contribute to the community knowledge and a shared knowledge objective [23]. In essence, in Knowledge Building, knowledge is viewed as a social product with students taking collective responsibility for the state of public knowledge and continual idea improvement [24], [25]. From a Knowledge Building perspective, the community succeeds through distribution of group effort across all members, not the concentration of efforts amongst a few individuals. Therefore, beyond ideas held privately by individuals, they should be made available to the community as publicly accessible artifacts that can be discussed, interconnected, revised, and superseded [26]. In fact, individual interests and expertise are complemented by those of the community as each individual tries to achieve both individual and community goals [27]. The exponential growth of Web 2.0 applications has facilitated the formation of such collaborative networks. The most widely used environment to support Knowledge Building and create collaborative networks in education settings is Knowledge Forum $\AA$ - a web-based discourse medium specifically designed to support production and refinement of community knowledge to advance understanding of the world and effective action through social interaction. Knowledge Forum with its specific design provides opportunities for students to act as knowledge workers in an open space [20].

\section{METHODOLOGY AND METHOD}

This study explores knowledge work within mature and novice knowledge building classes in two different classes; one class with mature Knowledge Building teacher and class, the other with both teacher and students new to Knowledge Building. A total of 40 Grade 5 students attended this study and explored Mathematics topics (e.g., proportion, measurement, patterning) using robotics: in the first class, the pedagogy of teaching and learning robotics was Knowledge Building, while in the second class the pedagogy of teaching and learning was CompetitionBased Learning. In the first class, students used Knowledge Forum to share their ideas, ask questions, and discuss about their problems with all other students in the community. However, in the second class, students used Knowledge Forum to discuss their ideas and problems only with their group members, not with all the students. I employed lexical analysis and Discourse Analysis in order to analyze students notes posted on Knowledge Forum and examine how student knowledge and ideas improved in these two different settings. Using a lexical analysis, I explored the words students used in their discourse and compare them with their curriculum math terms. Within the context of Knowledge Building, there are several studies in which the researchers examined the overlap between students discourse and expert discourse (e.g., 
[28]), and students discourse and curriculum glossaries (e.g., [29]). In such studies, the more students are talking scientifically (i.e. using words from expert corpus/ curriculum glossaries), the more they have met the learning expectations. I will compare the use of math terms in these two settings to explore which setting is more effective in terms of using math words. Second, I will conduct a Discourse Analysis (DA) in order to find evidence of idea improvement and scientific sophistication of ideas, which is the result of the spread of innovative ideas. DA is defined as "the study of the use of language for communication in context" [30] and Chai, Zhao, and $\mathrm{Mu}$ in [31] see discourse as means to test Vygotsky's ideas of interpersonal and inner speech [32].

\section{PRELIMINARY RESULTS}

So far, the first analysis (i.e. lexical analysis) has been done. The preliminary results of the study show that students in the first class (i.e. knowledge building class) used more math terms compare to the other class (i.e. competitive group). For example, Figure 1 shows the result of lexical analysis for class 1, and Figure 2 shows the result of lexical analysis for class 2 , in a week when the students were designing a robot to deliver food and medicine to refugees in a refugee camp.

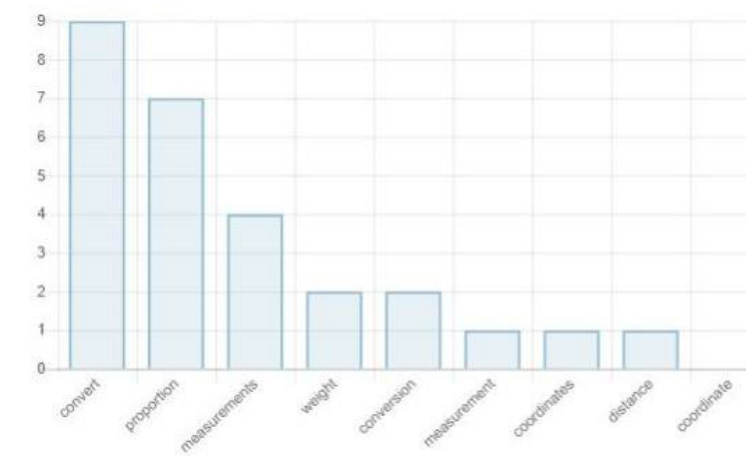

Figure 1. Math terms used by the students in the first class

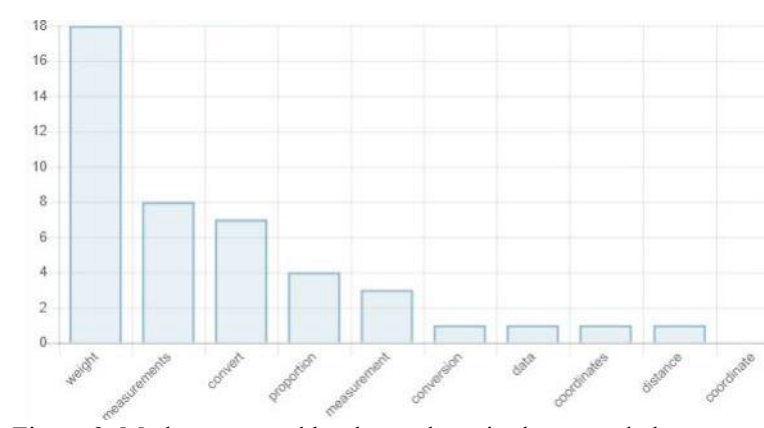

Figure 2. Math terms used by the students in the second class
As can be seen in these two figures, class 1 students talked more about advanced concepts compare to the other class. For example, compare to the second class, students in the first class more frequently used words like conversion, convert, proportion. This result shows that students in a knowledge building class, where a united community has formed, discussed advanced math concepts more than the other class. This can increase the chance of idea improvement and knowledge building about that concepts, because, from a sociocultural perspective of learning, the potential success or failure in education can be explained by the quality of discourse [33].

For the next step, I am planning to conduct the discourse analysis over students' notes and examine whether the discourse is really moving toward the knowledge objectives; which is idea improvement and knowledge advancement. SIGNIFICANCE OF THE STUDY

Although few students may grow up to be roboticists, all students in modern societies will have their lives affected by robotics. Learning about it is important, as is acquiring hands-on experience with it. But compartmentalized learning is not enough. It is important to have a community in which there are not insiders and outsiders but one where everyone can move between roles of doer, explainer, and critic. While educational robotics often goes on in a competitive way, which usually creates a dichotomy in which talented students are the winners at the expense of less talented students, this is the first study which employs Knowledge Building to create a united community to teach robotics. In such an environment, students are enculturated to take high-level collective responsibility to advance the community knowledge, because community and individual achievement go hand in hand. That is why this research, which treats robotics within the context of a collaborative knowledge-building community, offers both a wider perspective and a deeper approach to this 21 st century phenomenon.

\section{REFERENCES}

[1] Attard, C. (2012). Teaching with technology: Exploring the use of robotics to teach mathematics. Australian Primary Mathematics Classroom, 17(2), 31-32.

[2] Bers, M., \& Portsmore, M. (2005). Teaching partnerships: early childhood and engineering students teaching math and science through robotics. Journal of Science Education and Technology, 14(1), 59-74.

[3] Gura, M. (2012). Lego robotics: STEM sport of the mind. Learning and Leading with Technology, 40(1), 12-16.

[4] Giannakopoulos, N. (2009, September). Experiences from WRO 2009 competition and 
verifications about the robotics incorporation in the school. Paper presented at the Lessons Learnt from the TERECoP Project and New Pathways into Educational Robotics across Europe, Athens, Greece. [4] Kanda, T., Shimada, M., \& Koizumi, S. (2012). Children learning with a social robot. In the Proceedings of the 7th annual ACM/IEEE International Conference on Human-Robot Interaction (pp. 351-358). ACM, New York: NY.

[5] Johnson, R. T., \& Londt, S. E. (2010). Robotics competitions: The choice is up to you! Techdirections, 69(6), 16-20.

[6] Welch, A. (2010). Using the TOSRA to assess high school students' attitudes toward science after competing in the FIRST Robotics Competition: An exploratory study. Eurasia Journal of Mathematics, Science, \& Technology Education, 6(3), 187-197.

[7] Altin, H., \& Pedaste, M. (2012). Learning approaches to applying robotics in science education. Journal of Baltic Science Education, 12(3), 365-377.

[8] Jung, S. (2012). Experiences in developing an experimental robotics course program for undergraduate education. IEEE Trans Educ, 56, 129 136.

[9] Lawrence, R. (2004). Teaching data structures using competitive games. IEEE Transactions on Education, 47(4), 459-466.

[10] Verhoeff, T. (1997, December). The role of competitions in education. Paper presented at the Future World: Educating for the 21st Century: a conference and exhibition at IOI 1997, Cape Town, South Africa.

[11] Murphy, R. R. (2000).Using robot competitions to promote intellectual development. AI Magazine, 21(1), 77-90.

[12] Lam, S., Yim, P., Law, J., \& Cheung, R. (2001, August). The effects of classroom competition on achievement motivation. Paper Presented at the 109th Annual Conference of American Psychological Association (APA 2001), Washington, D.C.

[13] Vockell, E. (2004). Educational psychology: A practical approach. Purdue University.

[14] Hallak, F., Armoni, M., \& Ben-Ari, M. (2015). The effectiveness of robotics competitions on students' learning of computer science. Olympiads in Informatics, 9, 89-112.

[15] Johnson, D., Johnson, R., \& Smith, K. (1991). Active learning: Cooperation in the college classroom. Edina, MN: Interaction.

[16] Cohen, E.G., Brody, C., \& Sapon-Shevin, M. (Eds.) (2004). Teaching cooperative learning: The challenge for teacher education. Albany, NY: Suny Press.

[17] Kohn, A. (1992). No contest: The case against competition. Boston: Houghton Mifflin.
[18] Denis, B., \& Hubert, S. (2001). Collaborative learning in an educational robotics environment. Computers in Human Behavior, 17, 465-480.

[19] Karahoca, D., Karahoca, A., \& Uzunboylu, H. (2011). Robotics teaching in primary school education by project based learning for supporting science and technology courses. Procedia Computer Science, 3, 1425-1431

[20] Scardamalia, M. (2004). CSILE/Knowledge Forum. In A. Kovalchick, \& K. Dawson (Eds.), Education and technology: an encyclopedia (pp. 183192). Santa Barbara, CA: ABC-CLIO.

[21] Scardamalia, M., \& Bereiter, C. (2006). Knowledge building: Theory, pedagogy, and technology. In R. K. Sawyer (Ed.), The Cambridge handbook of the learning sciences (pp. 97-115). Cambridge University Press.

[22] Bereiter, C., \& Scardamalia, M. (1993).

Surpassing ourselves: an inquiry into the nature and implications of expertise. Chicago: Open Court.

[23] Bereiter, C., Scardamalia, M., Cassells, C., \& Hewitt, J. (1997). Postmodernism, knowledge building, and elementary science. The Elementary School Journal, 97(4), 329.

[24] Bereiter, C. (2002). Education and mind in the knowledge age. Mahwah, NJ: Erlbaum.

[25] Scardamalia, M. (2002). Collective cognitive responsibility for the advancement of knowledge. In B. Smith (Ed.), Liberal education in a knowledge society (pp. 67-98). Chicago, IL: Open Court. [26] Scardamalia, M., \& Bereiter, C. (2003). Knowledge Building. In Encyclopedia of education (1370-1373). New York: Macmillan Reference, USA. [27] Amar, A. D. (2002). Managing knowledge workers: Unleashing innovation and productivity. Westport, CT: Quorum Books.

[28] Resendes, M. (2014). Enhancing Knowledge Building discourse in early primary education: Effects of formative feedback. Doctoral dissertation, University of Toronto.

[29] Costa, S. (2016). Math discourse in a Grade 2 Knowledge Building classroom. Master's thesis, University of Toronto.

[30] Georgakopoulou, A., \& Goutsos, D. (2004). Discourse analysis: An introduction. Edinburgh: Edinburgh University Press.

[31] Chai, S., Zhao, J., \& Mu, S. (2011). Discourse analysis of collaborative meaning making in CSCL. In H. Spada, G. Stahl, N. Miyake, \& N. Law (Eds.), CSCL2011 Conference Proceedings (pp. 898-900). International Society of the Learning Sciences (ICLS). [32] Feigenbaum, P. (2009). Private speech: Cornerstone of Vygotsky's theory of development of higher psychological processes. In D. Robbins, \& A. Stetsenko (Eds.), Voices within Vygotsky's non- 
classical psychology: Past, present, future (pp. 161174). New York: Nova Science Publishers.

[33] Mercer, N. (2004). Sociocultural discourse analysis: Analysing classroom talk as a social mode of thinking. Journal of Applied Linguistics, 1(2), 137168. 